УДК 550.814:528.71

Харченко В.М.* Северо-Кавказский федеральный университет, Лапта Д.В.

\title{
НОВЫЙ СТРУКТУРНО-МЕТРИЧЕСКИЙ МЕТОД ВЫЯВЛЕНИЯ ПЕРСПЕКТИВНЫХ СТРУКТУР НА НЕФТЬ И ГАЗ (на примере Нурин-Хагской площади в Калмыкии)
}

Введение:

Материалы и методы исследований

Результать исследований

Обсуждения

и заключение:

Ключевые слова: актуальность исследований по разработке нового наиболее сравнительно мало затратного метода обусловлена необходимостью повышения эффективности не только поисков и разведки, но и разработки месторождений нефти и газа в России. Предлагается новый метод выявления перспективных структур на нефть и газ, основанный на теоретических представлениях о природе структур центрального типа (СЦТ), где установлена закономерная связь радиусов СЦТ с глубинами до плотностных неоднородностей, согласно закону скалывающих напряжений.

исходными материалами научных исследований являются космические снимки различных масштабов, данные почвенных, геоботанических, геоморфопогических (ландшафтно-геоэкологических) исследований для подтверждения достоверности выделенных структур центрального типа и линиментов различного ранга. Основным методом представпяется малоизвестный метод ландшафтно-геоэкопогического картирования, который является логическим усовершенствованием известного метода групповой геологической сьемки.

согласно представлениям о природе структур центрального типа (СЦТ), установлена закономерная связь радиусов СЦТ с глубинами до плотностных неоднородностей и геодинамическим центрам. Это объясняется известным в физике законом скапывающих напряжений, которые распространяются под углом 45 градусов по отношению к нормальным (вертикальным). Разработан новый метод выявления перспективных структур на несть и газ, приводится наглядный пример использования этого метода, на одной из перспективных площадей на территории Калмыкии, где теоретическая геолого-тектоническая модель подтверждена геофизическими и геохимическими исследованиями.

новый структурно-метрический метод является принципиально новым, сравнительно дешевым и доступным для применения, в какой-то мере существенным дополнением и развитием давно известного структурногеоморфопогического метода, и в какой-то мере аналогом структурнометрического метода Жукова В. Т., Лазарева Г. Е. и др. (1999) [2]. структурно-метрический метод, космическая сьемка, структуры центрального типа, закон скалывающих напряжений, геолого-тектоническая модель, Нурин-Хагская космосотоаномалия, сейсмические и геохимические исследования. 
Kharchenko V.M

Lapta D.V. North Caucasus Federal University, Stavropol, Russia

\section{NEW STRUCTURAL-METRIC METHOD FOR DETECTING PERSPECTIVE OIL AND GAS STRUCTURES (on the example of nurin-khagsky square in kalmykia)}

Introduction

Materials and research methods:

Research results:

Discussions and conclusion:

Keywords: inhomogeneities is established, according to the law of shear stresses. group geological filming geochemical studies. the relevance of research on the development of the most comparatively less costly method is due to the need to increase the efficiency not only of prospecting and exploration, but also the development of oil and gas fields in Russia. A new method is proposed for identifying promising structures for oil and gas, based on theoretical ideas about the nature of central type structures (CTS), where a regular connection of CST radii with depths to geological and geophysical

the source materials of scientific research are space imagery of various scales, data from soil, geobotanical, geomorphological (landscape-geoecological) studies to confirm the reliability of selected structures of the central type and liniment of various ranks. The main method is a little-known method of landscape-geoecological mapping, which is a logical improvement of the well-known method of

according to the concept of the nature of the central type structures (SCR), a regular connection has been established between the SCR radii and depths to geological and geophysical inhomogeneities and geodynamic centers. This is explained by the law of shear stresses, known in physics, which propagate at an angle of 45 degrees relative to normal (vertical). A new method for identifying promising structures for oil and gas has been developed, and a vivid example of using this method is given on one of the promising areas in Kalmykia, where the theoretical geological and tectonic model has been confirmed by geophysical and

the new structural-metric method is fundamentally new, relatively cheap and available for use, to some extent a significant addition and development of the well-known structural-geomorphological method, and to some extent analogous to the structural-metric method of Zhukov V. T., Lazareva, G. E., et al. (1999) [2].

structural-metric method, space imagery, structures of the central type, the law of shear stresses, geological-tectonic model, Nurin-Khag cosmo-anomaly, seismic and geochemical studies.

\section{Введение}

Предложенный структурно-метрический метод по представлениям авторов является «зеркальным отражением» известного и наиболее практически используемого в настоящее время сейсмического метода 3D. При сейсмических исследованиях, при создании разрядки импульсных полей напряжений (взрывах в приповерхностных условиях) по характеру прохождения продольных и поперечных волн регистрируют плотностные неоднородности или отражающие горизонты в земной коре и мантии. Настоящим же методом следы разрядки как импульсных, так и постоянно действующих напряжений в различных точках геолого-геофизических сред, соответствующих отражающим горизонтам или плотностным неоднородностям, фиксиру- 
ются на земной поверхности, и в разной степени достоверности диагностируются на аэро- и космических снимках различного масштаба в форме кольцевых структур или дуг-концентров различного радиуса соответствующим глубинам до плотностных неоднородностей в земной коре, мантии и даже в ядре, начиная с глубин первых десятков и сотен метров.

Это происходит потому, что различные по физико-механическим свойствам пород, литологические слои (отражающие горизонты), при пульсационном режиме Земли излучают волны тектонических напряжений или сейсмические волны из различных энергогенерирующих центров преимущественно в двух направлениях: вертикально вверх - нормальные напряжения и под углом 45 градусов по отношению к нормальным - максимальные касательные напряжения (согласно данным М.В. Гзовского, 1975) [1]. Указанные напряжения создаются архимедовой силой над залежами углеводородов или другими аномалиями низкой плотности в земной коре и мантии.

Волны импульсных или постоянно действующих тектонических напряжений проявляются на земной поверхности (в ландшафтах) и соответственно на высокочувствительных фотопленках при аэро- и космофотосъемке, в виде структур центрального типа (СЦТ) или кольцевых структур округлой формы в плане с характерной центральной симметрией и формой перевернутого конуса в объёме. Максимальные «следы» тектонических напряжений проявляются как в центральных частях, так и по периферии кольцевых структур или СЦТ в соответствии с разрядкой нормальных и максимальных касательных напряжений.

Учитывая, что эти напряжения распространяются под углом 45 градусов по отношению к нормальным (вертикальным), становится очевидно соответствие радиусов кольцевых структур и глубин до энергогенерирующих центров, а также кольцевая форма аэро- и космофотоаномалий.

Как уже было сказано выше, тектонические напряжения в основном связаны с реализацией закона Архимеда в природе, т. е. с наличием разности плотностей горных пород в геологической среде: в земной коре, мантии и даже ядре. Дифференциация вешества по плотности, как известно, происходит в результате вращения Земли вокруг своей оси, вокруг Солнца и центра Галактики. В земной коре зоны разуплотнения связаны с породами кислого состава (магматические диапиры), соленосными и глинистыми толщами (соляные и глиняные диапиры) и, наконец, нефтегазовыми залежами (нефтяные диапиры) [4].

Для последних характерны особые геодинамические условия и характерные проявления на земной поверхности: особый рисунок фотоизображения и речной сети, сравнительно низкие (по сравнению с газовыми залежами) градиенты скоростей движения земной коры. Эти представления изложены в работах Н.В. Розанова (70-е гт.) и В.В. Дроздова и др. (2000 г.) [3], в последних приводятся статистические данные по Ставропольскому краю о соответствии градиентов скоростей вертикальных движений и залежей нефти или газа. 


\section{Материалы и методы исследований}

Конкретный анализ СЦТ с использованием структурнометрического метода проводился на отдельных участках опытных работ на территории Северного Кавказа и Предкавказья.

Наиболее удачным примером является комплексная интерпретация Нурин-Хагской кольцевой космофотоаномалий (ККФА) на территории Калмыкии [6].

Нурин-Хагская кольцевая космофотоаномалии впервые была выявлена при дешифрировании космических фотоснимков черно-белого изображения и фотопланов масштаба 1: 200000, при выполнении работ тематической партией треста «Калмнефтегазразведка» по теме: «Обобщение геолого-геофизических и аэрокосмических материалов, территории Калмыкии с целью прогноза нефтегазоносности структур», автор В. М. Харченко, Элиста-Саратов 1981 г.

Нурин-Хагская ККФА представляет собой структуру центрального типа с выраженной центральной частью диаметром около 8 км, к которому приурочивается соленое мелкое озеро Нурин-Хаг (по которому и получила название КФАА) и ряд параллельно-расположенных бугров длинной 1-3 км, шириной 200-300 м, высотой до 10 м (рис. 1-2). Эти резко выраженные аномальные возвышенности аналогичны буграм Бэра, имеющие распространение в основном по побережью Каспийского моря, в остальных местах они распространены локально и обычно приурочиваются к уникальным участкам, связанных со своеобразием тектоники и проявление физических полей, в частности электромагнитных. По представлению автора, бугры Бэра являются результатом избирательной эоловой седиментации при работе природного электрофильтра-пылеуловителя. Последний, по аналогии с искусственным электрофильтром-пылеуловителем, работает в таком же режиме при электромагнитном взаимодействии заряженных пылевых облаков с проводящими электричество земными поверхностями в зонах пересекающихся тектонических нарушений. Таким образом, бугры Бэра являются индикатором «живых» тектонических нарушений, которые приурочиваются к центральной части кольцевой космофотоаномалии

Периферическая часть ККФА с большой достоверностью, диагностируется по системе кулисообразно расположенных тонких (до 200 м) дугообразных «полос» на космических снимках черно-белого изображения, снятых в обычном диапазоне спектра.

По мелкомасштабным КФС внешний контур Нурин-Хагской ККФА диагностируется в основном по косвенным признакам : по условным центрам мелких структур (до 8 км) центрального типа, расположенных, как правило, по главной «орбите» основной структуры , а также по системе солончаковых понижений, расположенных в целом по внешнему контуру СЦТ. Кроме того, в целом Нурин-Хагская ККФА ограничивается системой линеаментов 


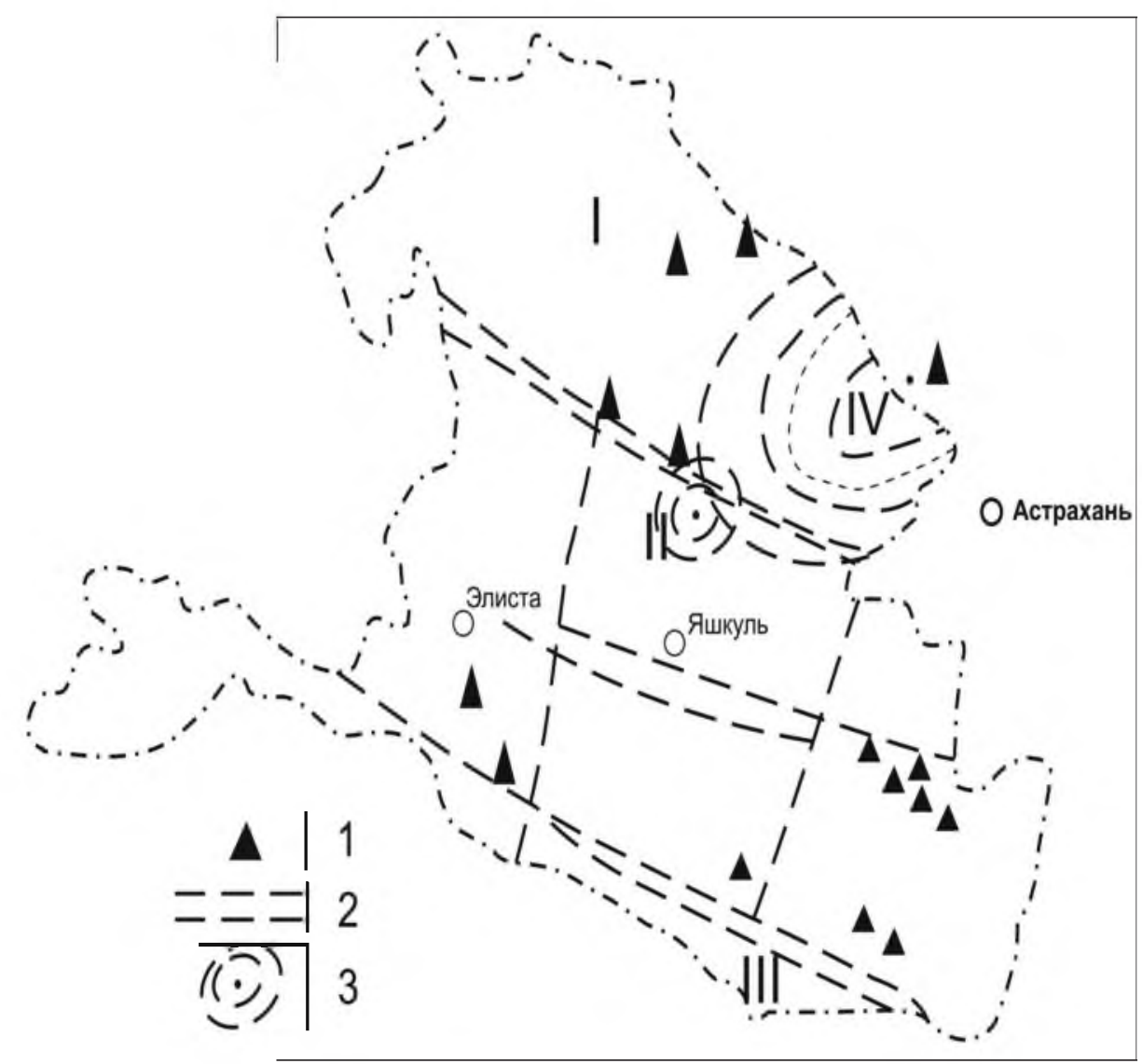

Рис. 1.

Схема расположения Нурин-Хагской космофотоаномалии на территории Калмыкии: I - Прикаспийская впадина, II Кряж Карпинского, III - Кумо-Манычская впадина, IV - Астраханский свод. 1 - Месторождение нефти и газа, 2 - Зона тектонических нарушений, 3 - кольцевые структуры.

Fig. 1. The layout of the Nurin-Khag cosmophotoanomaly on the territory of Kalmykia: I - Caspian depression, II - Karpinsky ridge, III - Kumo-Manych depression, IV - Astrakhan arch. 1 - Oil and gas field, 2 - zone of tectonic disturbances, 3 - ring structures.

субширотного, субмеридионального, северо-западного и северо-восточного направлений, в плане составляющие своеобразный шестиугольник с длиной стороны 8-10 км. К этому шестиугольному блоку в плане и приурочивается структура центрального типа с выраженной центральной частью диаметром около 8 км. К северо-востоку от этого центра, который четко отражается на космических снимках среднего и мелкого масштаба, выделяется своеобразная морфоструктура размера около 8 км, которая представляет собой в рельефе дефляционную котловину, с характерным понижением в центральной час- 


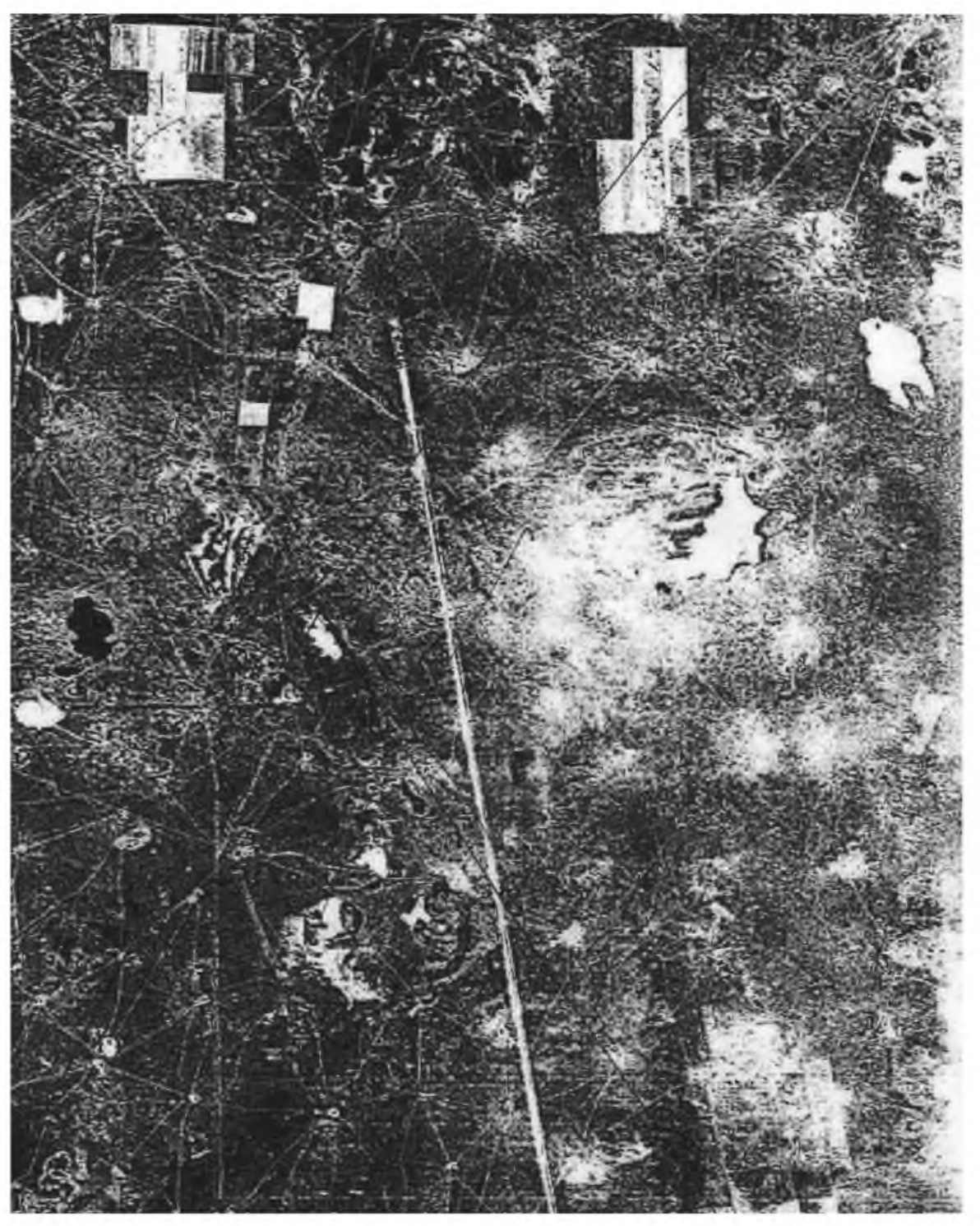

Рис. 2.

Космический снимок Нурин-Хагской площади в Калмыкии.

Fig. 2. Satellite image of Nurin-Khagskaya Square in Kalmykia.

ти. Это очень редкий случай развития локальной эрозионной сети временных и постоянных водотоков на фоне аккумулятивного типа рельефа Прикаспийской низменности. Кроме того, это явный признак современной структуры растяжения в центральной части сводового неотектонического поднятия на обшем фоне опускания земной поверхности в пределах Прикаспийской низменности, где, как известно, выделяется морская верхнехвалынская аккумулятивная равнина. По восточному контуру этого неотектонического поднятия располагается цепочка солончаковых понижений, центральная его часть совпадает с озером Нурин-Хаг. К северо-востоку от выделенной Нурин-Хагской ККФА имеют широкое распространение многочисленные дефляционные кот- 


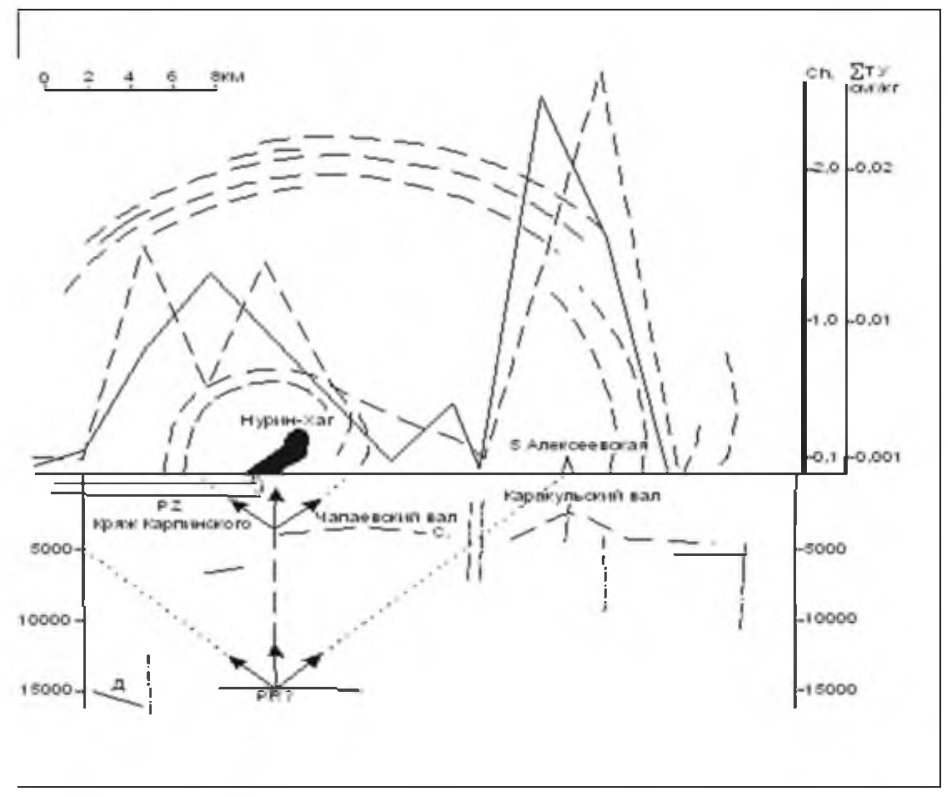

Рис. 3.

Схема приуроченности геохимических аномалий по метану и тяжелым углеводородам к космофотоаномалии и зонам тектонической трещиноватости на Нурин-Хагской площади. (Автор В.М. Харченко по материалам треста «Калмнефтегазразведка»): 1 - Контуры структур центрального типа; 2 - Распространение нормальных и максимальных касательных; 3 - Значение содержания углеводородов; 4 - Основные отражающие горизонты; 5 - Тектонические нарушения; 6 - Скважина с газопроявлением.

Fig. 3. Scheme of geochemical anomalies associated with methane and heavy hydrocarbons to cosmophotoanomaly and tectonic fracture zones in Nurin-Khag area. (Author VM Kharchenko according to the materials of the Kalmneftegazrazvedka trust): 1 - Outlines of structures of the central type; 2 - Distribution of normal and maximum tangents; 3 - The value of the content of hydrocarbons; 4 - Main reflecting horizons; 5 - Tectonic disturbances; 6 - Gas well.

ловины в отличие от описанной выше, окаймленные песчаными буграми и барханами. Они, как правило, все приурочиваются к неотектоническим поднятиям, размеры их примерно соответствуют вышеописанной (от 3 до 5 км в поперечнике), но отличаются песчаной литологической основой, а не глинистой, что характерно для нашего нового объекта, и отсутствием явно выраженной эрозионной сети. Для песчаных дефляционных котловин Калмыкии (Юстинский район) характерна приуроченность линз пресных и солоноватых вод, а в центре одной из них было открыто в 1987 г. Северо-Шаджинсое газопроявление (рис. 3) в триасовых отложениях на глубинах около 3 км. В непосредственной близости от дефляционной котловины в пределах Нурин-Хагс- 
кой ККФА в 70-е годы, на Алексеевской площади (скв. 5 ) был получен фонтан газа с глубины около 2 км, однако при бурении скв. 8 в 2 км на северо-запад от скв. 5, нефтегазопроявлений на этой глубине не обнаружено.

Согласно теоретических разработок о природе структур центрального типа, изложенных автором в указанном отчете и представленных далее на международном геологическом конгрессе в г. Москве 1984 г. и в докладах различных научных конференциях в СевКавГТУ г. Ставрополе 1999-2000 гг., была разработана геолого-тектоническая модель (рис. 4) и сделан прогноз о возможной залежи УВ в подсолевых отложениях карбона на глубинах 3,5-4,0 км. Кроме того, согласно этой концепции, о соответствии радиусов глубинам до энергогенерирующих центров и геолого-геофизических отложений неоднородностей выделены важные интервалы глубин $\mathrm{H1}-2,2$ км, $\mathrm{H}_{2}-3,6$ км,

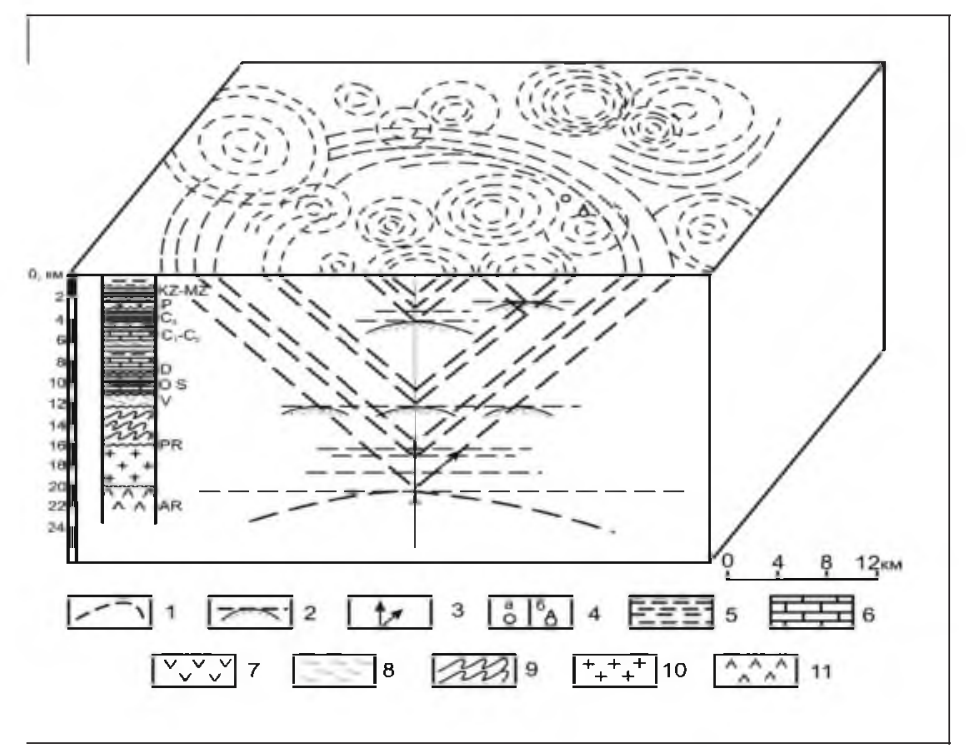

Рис. 4.

Теоретическая геолого-тектоническая модель Нурин-Хагской площади, составленная по результатам дешифрирования космических снимков и интерпретации полей напряжений: 1 - структурные линии структур центрального типа (СЦТ); 2 - геолого-геофизические разделы сред; 3 - распространение полей напряженности; 4 - скважины: а - пустая, б - газоносная; 5 - глины, аргиллиты; 6 - известняки; 7 - соли; 8 - сланцы; 9 - сложнодислоцированные породы; 10 - граниты; 11 - основные породы.

Fig. 4. Theoretical geological and tectonic model of Nurin-Khag area, compiled from the results of interpretation of satellite images and interpretation of stress fields: 1 - structural lines of the central type structures (CST); 2 - geological and geophysical sections of media; 3 - the spread of fields of tension; 4 - wells: a empty, $\mathrm{b}$ - gas-bearing; 5 - clay, argillite; 6 - limestone; 7 - salts; 8 - slates; 9 complex rocks; 10 - granites; 11 - the main breed. 


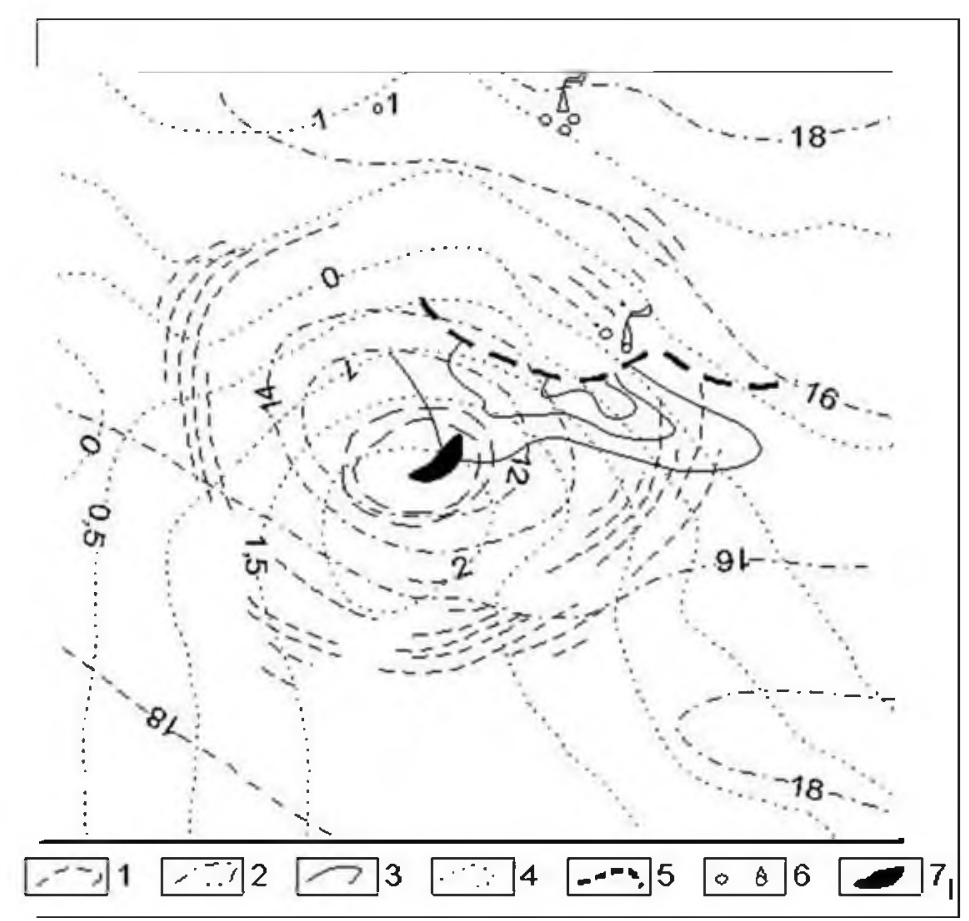

Рис. 5.

Схема сопоставления космофотоаномалии с различными геолого-геофизическими данными: 1 - структурные линии космофотоаномалии, 2 - изогипсы кровли докембрийского фундамента, 3 - изогипсы отражающего горизонта карбона (1 - п C2b), 4 - изолинии напряженности магнитного поля, 5 - разрывные нарушения (по данным геофизики), 6 - скважины: а - поисково-разведочные; 6 - в которых получен газ, 7 - оз. Нурин-Хar.

Fig. 5. Diagram of comparison of cosmophotoanomaly with various geological and geophysical data: 1 - structural lines of cosmophotoanomaly, 2 - roofing isohypsies of the Precambrian basement, 3 - isohypsies of the reflecting carbon fiber ( 1 - $n$ C2b), 4 - isolines of the magnetic field strength, 5 - discontinuous faults (according to geophysics), 6 - wells: a - exploration; b - in which gas is obtained, 7 - oz. Nurin-Hag.

$\mathrm{H}_{3}-12-13$ км, $\mathrm{H}_{4}-14-16$ км, $\mathrm{H}_{5}-20$ км. Наиболее выражены из перечисленных радиусов и соответственно глубины являлись: 3,6-4 км, 12-13 км и максимальные 20 км.

В начальный период анализа и сопоставления выделенной Нурин-Хагской ККФА с различными геофизическими материалами (рис. 5) была отмечена плановая приуроченность центральной части ККФА с аномалией магнитного поля (значение Т-2-3 миллиэрстед на нулевом фоне и отрицательных значений), а также плановое практически полное совпадение с выступом докембрийского фундамента на глубинах 1-14 км, выявленного в результате сейсмических исследований АГЭ ПГО «Центргеофизика». Центральная часть ККФА практически совпадает с изогипсой - 12 км докембрийского фундамента, а общий контур окаймляет изогипсой минус 18 км. Делается однозначный вывод, что в целом ККФА и ее центральная часть в первую оче- 
редь обусловлены горстообразным выступом кристаллического фундамента, который дополнительно подтверждается данными магнитометрии. Магнитная аномалия скорее всего связана с составом пород докембрийского фундамента (по аналогии с Украинским и Воронежским щитами), где широко развиты железистые кварциты докембрия, или наличием вулкано-плутонического центра девонского возраста, приуроченного к центральной части ККФА

В 1986-1987 гг., по инишиативе автора В.М. Харченко, будучи главным геологом Калмыцкой НГРЭ совместно с Саратовским университетом были проведены площадные и профильные геохимические исследования через центр ККФА и среднюю Алексеевскую площадь.

В результате этих работ были выявлены геохимические аномалии (по содержанию метана и суммы тяжелых УВ) в центральной части ККФА и в районе Алексеевской площади, скв. 5 (рис. 6).

При бурении скв. 5 Алексеевской площади в начале 70-х годов был получен фонтан газа с глубины 1700 м с кунгурских отложений нижней перми. Газопроявление было ликвидировано по техническим причинам. Рядом, в 2 км на северо-запад, была пробурена на такую же глубину скв. 8, где газопроявление не подтвердилось.

Факт газопроявление в скв. 5 был воспринят без должного внимания, и обоснования газопроявления не последовало, потому что перспективных объектов на этом стратиграфическом уровне на соседних областях не наблюдалось, а вероятность миграции УВ по зонам пересекающихся разломов из нижележащих горизонтов, к сожалению, не рассматривалась, поэтому площадь впоследствии считалась бесперспективной.

В этот же период, опять же по инициативе автора, в результате сейсмических работ Астраханской ГЭ ПГО «Центргеофизика» в пределах контура выделенной ККФА, в непосредственной близости от ее центральной части, была выделена Чапчаевская структура по горизонту С 31 П (C2b), с двумя локальными поднятиями на глубинах 3,6-3,65 км.

На данную структуру составлен паспорт с рекомендациями для последующего бурения, с рекомендациями по постановке бурения поисковых скважин с учетом интерпретации Нурин-Хагской ККФА, геофизических и геохимических материалов. При последующей интерпретации сейсмических материалов на этой площади был выделен так называемый Чапчаевский вал по отражающему горизонту ІП (С-Р) в пределах глубин 3800 - 5000 м. Чапчаевский вал с севера и юга ограничен зонами тектонических нарушений и представляет собой вытянутую с субширотном направлении структуру, аналогичную Каракульскому, Смушковскому и др. валообразным поднятиям в зоне сочленения кряжа Карпинского и Прикаспийской впадины. Даже при беглом анализе сейсмических профилей $(56.86,6.6 .86,7.6 .86,8.6 .86$ и др.) очевиден изометричный плановый рисунок структуры, а не линейный, как это отражено на всех опубликованных структурных карта. 
Рис. 6.

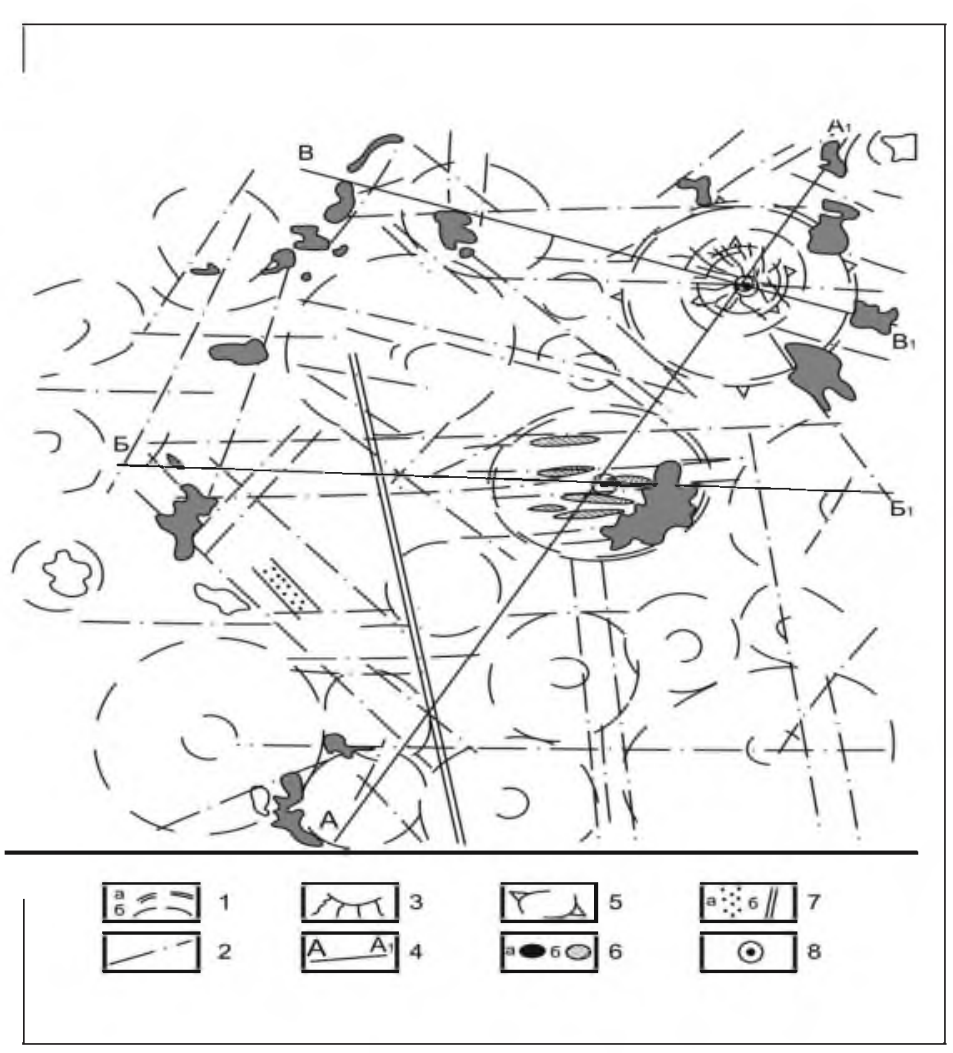

Схема дешифрирования Нурин-Хагской космофотоаномалии: 1 - контуры структур центрального типа (СЦТ): а - достоверные, 6 - предполагаемые; 2 - линеаменты и зоны тектонических нарушений: а -достоверные; 6 - предполагаемые; 3 - следы временных водотоков; 4 - рекомендуемые детальные грави- и сейсмопрофили; 5 - морфоструктура центрального типа с центростремительным рисунком гидросети (дефляционная котловина в центре); 6 - контуры: а - соленых озер и солончаков, 6 - бугров Бэра; 7 : а - песчаный массив, б - канал Волга-Чаграй (недостроенный); 8 - рекомендуемые поисковые скважины.

Fig. 6. Interpretation scheme of the Nurin-Khag cosmophotoanomaly:

1 - the contours of the central type structures (SCR): a - reliable, b - assumed; 2 - lineaments and zones of tectonic disturbances: $a$ - reliable; $b$ - supposed; 3 traces of temporary streams;

4 - recommended detailed gravity and seismic profiles:

5 - morphostructure of the central type with a centripetal pattern of the hydraulic network (deflationary depression in the center);

6 - contours: a - salt lakes and salt marshes, $b$ - Baer hillocks;

7 - a - sand massif, b - Volga-Chagray canal (unfinished);

8 - recommended prospecting wells. 


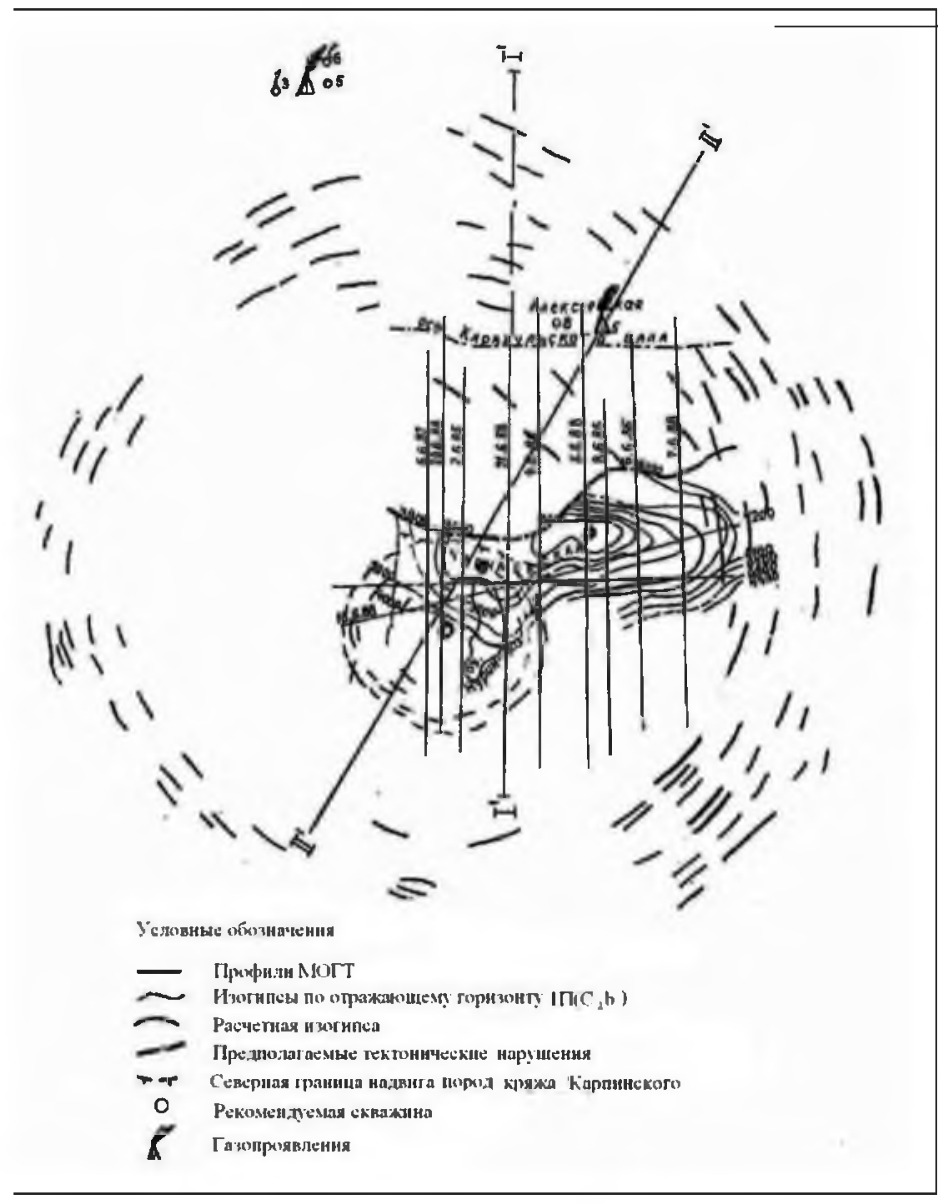

Pис. 7.

Схема приуроченности кольцевой космофотоаномалии к поднятию по отражающему горизонту $I \mathrm{ICC}_{2} \mathrm{~b}$.

Fig. 7. Scheme of confinement of the annular cosmophotoanomaly to the elevation along the reflecting horizon $\mathrm{IPC}_{2} \mathrm{~b}$

Следовательно, здесь выделяется брахиантиклинальная структура по отражаюшему горизонту IП $(\mathrm{C}-\mathrm{P})$ или $\mathrm{C}_{3} 1 \Pi\left(\mathrm{C}_{2} \mathrm{~b}\right)$ (рис. 7) размером в поперечнике около 25 км, которая унаследует структурный план докембрийского фундамента на глубинах 12-14 км.

Исходя из последних данных о нефтеносности девонских отложений в пределах Астраханского свода, залегающих там на глубинах 6 км (Володарская скв.) и их вероятного распространения по правобережью р. Волги, можно предполагать наличие нефтегазоносных залежей в пределах выделенной Нурин-Хагской космофотоаномалии, но уже на меньших глубинах, а именно: начиная с 4000 м залежи УВ могут быть приурочены как к карбонатных коллекторам девона, так и терригенно-карбонатным отложениям карбона, которые в целом образуют структуру облекания горстообразного докембрийского фундамента, выделяемого по последним данным на глубиннах $8-10$ км (Я.М.Бродский, Ю.Г.Юров - ГПО «Спецгеофизика», Ю.А. Воложь - ГИН РAН, 1977 г.). 
Покрышками предполагаемых залежей УВ в карбоне и девоне вполне могут служить соленосные отложения перми, которые вскрываются на этой площади на глубине около 2000 м.

\section{Результаты исследований и их обсуждение}

Таким образом, выделяемая Нурин-Хагская кольцевая космофотоаномалия подтверждается как перспективная структура на предмет поисков залежей нефти и газа как прямыми геохимическими, так и геофизическими, в частности сейсмическими методами исследования. Кроме того, газоносность подтверждена бурением скважины 5 Алексеевской.

Предложенный автором (Харченко В.М.) новый структурно-метрический метод, на основе трактовки механизма образования структур центрального типа, позволяет составить теоретическую геолого-тектоническую модель территории и выделить перспективные объекты на нефть и газ на конкретных глубинах, которые практически совпадают с данными геофизических и геохимических исследований.

\section{Выводы}

1. Предложенный новый структурно-метрический (сейсмоаэрокосмический) метод существенно отличается от ранее известных структурногеоморфологического и морфо-метрического методов. Отличается основательной теоретической базой, комплексным подходом и очевидной практической значимостью.

2. По примеру предложенной интерпретации и построения геолого-тектонической Нурин-Хагской структуры возможно его применение практически во всех регионах.

3. Теоретическая модель подтверждена геофизическими и геохимическими методами.

4. На Нурин-Хагской площади в Калмыкии рекомендуется бурение скважины на нефть и газ глубиной не менее 4 км.

\section{Библиографический список}

1. Гзовский М.В.. Тектонофизика. М.: Недра, 1975.

2. Жуков В.Т.. Новое использование данных аэрокосмической съемки для прогноза месторождений нефти и газа / В.Т. Жуков, Г.Е. Лазарев, М.Н. Ломоносов, В.В. Хвостов. М.: ВИНИТИ, 1999.

3. Дроздов В.В., В.П. Бигун, М.П. Голованов. Новейшая тектоника и нефтегазоносность Центрального Предкавказья. Сборник научных трудов. Серия «Тектоника и геодинамика». Вып. 1. Ставрополь, 2002. С. 8-16.

4. Смирнова С.Н. Нефтегазоносные кольцевые структуры и научно-методические аспекты их изучения. Библиотеки Дамирджани, Геология нефти и газы №9, 1997. 
5. Соловьев В.В. Структуры центрального типа территории СССР по данным геолого-геоморфологического анализа. Объяснительная записка к карте морфоструктур центрального типа территории СССР, масштаб 1:1000000. Л.: 1978.

6. Харченко В.М.. Природа структур центрального типа и закономерности распространения залежей углеводородов, локальных и региональных очагов землетрясений. Ставрополь: Вестник СевКавГТУ, №2(6). 2006. С. 48-53.

\section{References}

1. Gzovsky M.W. Tectonophysics. M.: Nedra, 1975. (In Russ.)

2. Zhukov V.T. New use of aerospace survey data for forecasting oil and gas fields / V.T. Zhukov, G.E. Lazarev, M.N. Lomonosov, V.V. Tails. M.: VINITI, 1999. (In Russ.)

3. Drozdov V.V., Bigun V.P., Golovanov M.P. The newest tectonics and oil and gas potential of the Central Ciscaucasia. Collection of scientific papers. Series "Tectonics and geodynamics." Issue 1. Stavropol, 2002. P. 8-16. (In Russ.).

4. Smirnov S.N. Oil and gas ring structures and scientific and methodological aspects of their study. Damirjani Libraries, Oil and Gas Geology, No. 9, 1997. (In Russ.)

5. Solovyov V.V. The structure of the central type of the territory of the USSR according to geological and geomorphological analysis. Explanatory note to the map of morphostructures of the central type of the territory of the USSR, scale 1 1,000,000. L.: 1978. (In Russ.).

6. Kharchenko V.M. The nature of the structures of the central type and the pattern of distribution of hydrocarbon deposits, local and regional earthquake sources Stavropol: Herald of North Caucasus State Technical University, №2 (6). 2006 C. $48-53$. (In Russ.).

\section{6 авторах}

Харченко Владимир Михайлович, Доктор геолого-минералогических наук, доцент кафедры геологии нефти и газа Северо-Кавказского федерального университета (СКФУ), 355000, г. Ставрополь, пр. Кулакова 16/1 (корпус 16) Телефон: +7(906)-468-22-64, E-mail: gng@ncstu.ru.

Лапта Денис Васильевич, аспирант кафедры геологии нефти и газа СевероКавказского федерального университета (СКФУ), 355000, г. Ставрополь пр. Кулакова 16/1 (корпус 16). Телефон: +7(906)-491-34-26, E-mail: d.lapta@ yandex.ru.

\section{About the authors}

Kharchenko Vladimir Mikhailovich, Doctor of Geological and Mineralogical Sciences, Associate Professor at the Department of Geology of Oil and Gas, NorthCaucasian Federal University (NCFU), 355000, Stavropol, 16/1 Kulakov Ave (building 16). Phone: +7(906)-468-22-64, E-mail: gng@ncstu.ru.

Lapta Denis Vasilievich, a graduate student of the Department of Oil and Gas Geology of the North Caucasus Federal University (NCFU), 355000, Stavropol, Klakova Ave. 16/1 (building 16). Phone: +7(906)-491-34-26, E-mail: d.lapta@yandex.ru. 